\title{
The difference between the vaccine and the GMO food debates
}

We are in a political moment where science is under attack. We recently attended one of the over 600 marches throughout the USA, where scientists and others rallied behind defending and protecting proven scientific facts as well as the resources necessary to fund important research. At the march, we saw numerous posters conflating the anti-vaccine and the anti-GMO movements - insinuating that to be skeptical of either is to be anti-science. This comparison was flouted at many of the marches and throughout social media for specific reasons. The agriculture biotechnology industry wishes its products to viewed as unfairly criticized by misinformed and misguided individuals and groups in the same way that activists who argue some vaccines can cause autism are viewed. There has been a move among skeptics themselves to make this analogy pointing to similarities in the industrial organization of the vaccine and GM crop sectors. However, despite that argument, and the fact that there are popular movements in opposition to vaccines and GM crops, the parellels end there.

For instance, the fears of 'anti-vaxxers' are based on a widely discredited theory. And, vaccines provide widespread and indisuputable public benefits. Many of us living in developed countries no longer have to fear measles, diphtheria, tetanus, cholera, plague, typhoid, tuberculosis and many other diseases. The anti-vaccine movement, which has been gaining steam in recent decades, has harnessed anti-scientific fears of a safe practice, which saves the lives of millions of people each year.

On the other hand, while a majority of studies find foods with genetically modified ingredients to be safe for human consumption, there are a minority of studies that find problems and these tend to involve kidney and liver functions. The minority studies are immediately attacked by industry and sympathetic academics, which discourages more investigation. Though we do not argue that GM crops, or the foods derived from them, are unsafe, there are other reasons to be skeptical of GM crops. Reasons that find no parellel in the vaccine controversy.

For example, the largest percentage of genetically engineered food crops are those that have been developed to be tolerant to herbicides ( $\mathrm{Ht}$ crops), which are sold to farmers from the same companies that sell them the $\mathrm{Ht}$ seeds. The widespread adoption of these crops has resulted in the development of herbicide-tolerant weeds, which in turn require the development of crops tolerant of additional herbicides. This requires farmers to pay for additional pesticide applications. In poorer nations especially, this can lead to increasing amounts of farmer debt.

Additionally, because companies that develop and sell genetically modified seeds have legal patents over their use, they can and do sue farmers with trace amounts of patented genetic material in their fields who do not have a licensing agreement with the company. Even if the presence of the patented material is caused by drifting pollen.

Still many people argue that GM cropss are necessary to 'feed the world' - that we have a lack of food available and that genetically modified crops, with their promoted higher yields, are the only way to feed a growing world population. Yet, genetically modified crops have not proven to be able to sustainably increase yields, and in some cases, have decreased yields. The truth is we already produce sufficient food to feed the world's population. The issue is not availability, but the lack of purchasing power or effective distribution to those in need. Therefore, it is proven that we do need vaccines to ehance public health; while similar arguments cannot be made plausibly for GM crops.

Despite this fact, the FDA is about to spend US\$3 million on a PR campaign promoting the ecological, humanitarian and health benefits of GM crops and the foods derived from them, as part of the new federal budget agreement. This is a clear use of public funds being used to benefit private corporations with few or no public benefits. Rather than increase spending which primarily or soley benefits private companies and undermines the rights of farmers, we need to see an increase in policies and funding for sustainable agricultural practices as well as innovative ways to get resources and food into communities where it is lacking. Public incentives for grocery stores that pay living wages to open in food deserts and funds to support existing projects such as urban gardens and food hubs will help feed hungry communities - not increasing the use of a suite of technologies with serious shortcomings.

By labeling convincing and well-founded political and economic critiques of GM crops as anti-science, we are doing a disservice to a true understanding of science and relatedly, of sustainable and renewable food systems. While it is valid for people to be concerned about vaccines and their health and safety-it is a closed case. Alternately, in the case of GM crop, the concerns are less about safety and more about a broader set of issues - namely political and economic ones which are yet to be addressed by GM crop proponents. 
Laura-Anne Minkoff-Zern is an Assistant Professor of Food Studies in Falk College at Syracuse University. She is currently working on a book, titled, 'The New American Farmer: Race, Immigration, and the Struggle for Sustainability.'

Rick Welsh is the Falk Family Endowed Professor of Food Studies in Falk College and Chair of the
Department of Public Health, Food Studies, and Nutrition at Syracuse University and Editor-In-Chief for the journal Renewable Agriculture and Food Systems.

Laura-Anne Minkoff-Zern and Rick Welsh*

*Corresponding author: jrwelsh@syr.edu 